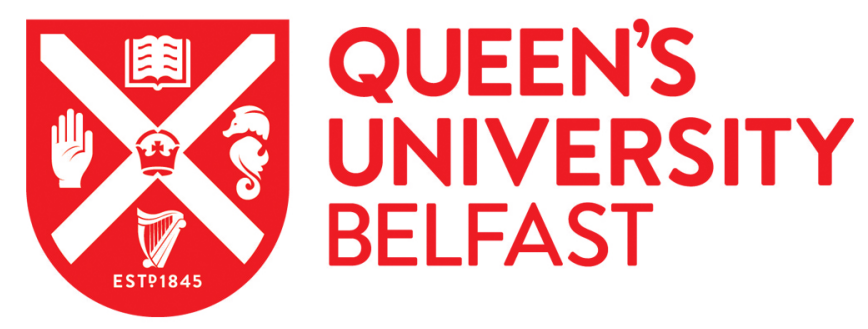

\title{
Barriers to adopting a Mediterranean diet in Northern European adults at high risk of developing cardiovascular disease
}

Moore, S. E., McEvoy, C. T., Prior, L., Lawton, J., Patterson, C. C., Kee, F., Cupples, M., Young, I. S., Appleton, K., McKinley, M. C., \& Woodside, J. V. (2017). Barriers to adopting a Mediterranean diet in Northern European adults at high risk of developing cardiovascular disease. Journal of human nutrition and dietetics : the official journal of the British Dietetic Association. https://doi.org/10.1111/jhn.12523

Published in:

Journal of human nutrition and dietetics : the official journal of the British Dietetic Association

Document Version:

Peer reviewed version

Queen's University Belfast - Research Portal:

Link to publication record in Queen's University Belfast Research Portal

Publisher rights

(c) 2017 The British Dietetic Association Ltd. This work is made available online in accordance with the publisher's policies. Please refer to any applicable terms of use of the publisher

\section{General rights}

Copyright for the publications made accessible via the Queen's University Belfast Research Portal is retained by the author(s) and / or other copyright owners and it is a condition of accessing these publications that users recognise and abide by the legal requirements associated with these rights.

Take down policy

The Research Portal is Queen's institutional repository that provides access to Queen's research output. Every effort has been made to ensure that content in the Research Portal does not infringe any person's rights, or applicable UK laws. If you discover content in the Research Portal that you believe breaches copyright or violates any law, please contact openaccess@qub.ac.uk. 
1 Barriers to adopting a Mediterranean diet in Northern European adults at high risk of

Abstract

\section{Background}

Strong evidence links consumption of the Mediterranean diet (MD) to a reduced cardiovascular disease (CVD) risk, however there is uncertainty whether non-Mediterranean regions will adopt this diet. This qualitative research aimed to investigate attitudes towards a MD in individuals at high CVD risk in a Northern European population. This information is needed to inform development of MD interventions in non-Mediterranean high-risk populations.

\section{Methods}

Focus groups $(\mathrm{n}=12)$ were held with individuals at high CVD risk from Northern Europe $(\geq 2$ CVD risk factors, aged $\geq 50$ years, no established CVD/ type 2 diabetes). Attitudes to dietary change

\section{Results}

Sixty-seven adults participated (60\% female, mean age 64 years). There was some awareness of the term MD but limited knowledge of its composition. Barriers to general dietary change were evident including perception of expense, concern over availability, expectation of time commitment, limited knowledge, lack of cooking skills, amount and conflicting nature of media information on diets, changing established eating habits and resistance to dietary change. Barriers specific to MD adoption were also identified, including perceived difficulty living in a colder climate, perceived impact on body weight, acceptability of a MD and cultural differences.

\section{Conclusions}

Knowledge of a MD was limited in this Northern European sample at high CVD risk. In addition to general barriers to dietary change, barriers specific to a MD were identified. These findings have implications for the development of interventions to promote MD adoption in non-Mediterranean populations. 


\section{Introduction}

3 Cardiovascular disease (CVD) is a leading cause of morbidity and mortality globally and is therefore a major public health concern ${ }^{(1)}$. Strong evidence supports consumption of the Mediterranean diet (MD) for a reduction in CVD risk ${ }^{(2)}$. A meta-analysis of cohort studies investigating the effects of adherence to the MD on health status found that a two-point increase in Mediterranean diet score was associated with a $10 \%$ reduction in risk of CVD incidence or mortality ${ }^{(3)}$. The PREDIMED study, a recent primary prevention trial of MD with CVD outcomes, showed a 30\% reduction in CVD risk with consumption of a MD supplemented with olive oil or nuts, in comparison with a low fat diet after five years ${ }^{(4)}$. Further PREDIMED analyses highlighted that MD adherence led to significant improvements in CVD risk factors ${ }^{(5,6)}$. Additional RCTs also demonstrate a cardio protective effect of the $\mathrm{MD}^{(7,8)}$. The MD is largely based on fruit and vegetables and wholegrain cereal products; moderate amounts of dairy products, fish and poultry; and small amounts of red meat and sweet foods. Olive oil is the main fat source in the diet and wine is consumed in moderation ${ }^{(9)}$.

Although the health benefits of following a MD are well established, there is uncertainty about whether non-Mediterranean regions will adopt this diet. The typical diet consumed by UK adults is considerably different to the MD, being low in fruit and vegetables, legumes, oily fish and wholegrains and high in saturated fat and sugar ${ }^{(10,11)}$. Additionally, research suggests that it can be difficult to follow a MD outside a Mediterranean region ${ }^{(12)}$. Intervention studies to encourage MD adoption conducted in Northern European populations, although limited in number, have reported increases in MD adherence ${ }^{(13,14)}$. Understanding the practical, cultural and other factors that may affect dietary behaviour change towards a MD in non-Mediterranean populations is essential when trying to guide this type of dietary change. While barriers to general dietary change are well documented in the literature ${ }^{(15-19)}$, there is very limited information on specific barriers that may exist in relation to adoption of a MD by Northern European populations. To our knowledge, only two small qualitative studies have investigated barriers to consuming a MD in the UK in one region $^{(20,21)}$. These studies represent the views of healthy adults, however, it is critical to gain insight into the views of adults at high CVD risk, who may gain the greatest health benefits from changing to a MD and who a MD intervention would ideally target. As eating habits in Northern Ireland (NI) are less optimal than the UK as a whole ${ }^{(22)}$, there is a particular need to target this UK region with MD advice. Research is needed to explore attitudes towards this dietary pattern in a Northern Irish population at high CVD risk to guide development of appropriate MD behaviour 
1 develop interventions that are effective in facilitating dietary behaviour change towards a MD that could be rolled out at the population level.

4 Following the MRC framework for the design and evaluation of complex interventions to improve health $^{(23)}$, this research aimed to explore attitudes towards consuming a MD in individuals at high CVD risk from a Northern European population to inform the development of a MD intervention in this group. Involvement of the target population in the early stage of intervention development is needed to better understand the factors influencing behaviour and what needs to shift for the desired behaviour to occur. This approach will help to tailor a MD intervention accordingly and maximise

\section{Materials and Methods}

\section{Study design and participants}

Focus groups were used to provide an insight into group norms rather than individual preferences $^{(24)}$. A purposive sample was recruited of individuals with $\geq 2$ CVD risk factors (overweight/ obese, hypertension, hypercholesterolemia and smoking) but having no medical history of CVD or type 2 diabetes and aged $\geq 50$ years, as this age group is at higher risk of developing CVD. Participants were recruited through making contact with community health centres and community group networks; screening by general practices for individuals that met the inclusion criteria followed by an invitation by letter; and telephone invitations being extended to individuals who had participated in previous dietary interventions at the research centre. Ethical approval was given by the Office for Research Ethics Committees Northern Ireland (Reference:13/NI/0152) and participants provided written informed consent. The study was conducted between December 2012 and July 2013. Participant travel expenses were reimbursed.

Recruitment was undertaken to obtain a diverse sample in terms of gender, age and geographical location (urban/rural). Focus groups were assembled to be homogeneous with regards to gender and geographical location (urban/ rural), as it has been suggested that individuals more readily disclose

Participants completed a demographic, lifestyle and medical information questionnaire which also assessed awareness of the MD, awareness of the link between CVD risk and diet and willingness to 
1 Food Frequency Questionnaire (FFQ) to provide information on consumption of key MD 2 components. This FFQ was based on a validated 14-item Mediterranean diet score (MDS) used in a 3 previous MD intervention ${ }^{(26)}$ but shortened for accessibility within the focus group setting and adapted for a Northern European population. Adaptations comprised of rapeseed oil being included, as it is a locally available alternative with a favourable fatty acid profile ${ }^{(27)}$. Consumption of legumes was assessed in combination with vegetables, as in Northern European populations, legume consumption is low ${ }^{(10)}$. Oily fish was specified due to being high in omega-3 fatty acids which have significant health benefits for this population ${ }^{(28)}$. Additionally, consumption of wholegrains was included to reflect current guidelines for consuming a $\mathrm{MD}^{(9)}$. This was used to calculate an 8-point MDS for each participant. Scoring criteria was based on the validated $\operatorname{MDS}^{(26)}$ the FFQ was developed from and MD guidelines ${ }^{(9)}$. Serving amounts of MD components were based on UK dietary guidelines. A score of 0 represented the lowest adherence to a MD and 8 represented greatest adherence (Supplementary material, Table S1).

\section{Focus group procedure}

Two researchers conducted the focus groups (SM, CME), with one acting as facilitator and one as an assistant to ensure all topic areas were adequately covered in the discussion. At the start of the discussion the facilitator introduced themself and explained that they were a University researcher. Effort was taken to minimise social differences between the researcher and group that may affect responses through establishing a sense of commonality and creating a non-judgemental atmosphere $^{(29)}$. To reduce bias arising due to the views of one individual affecting another or overrepresentation of the views of more dominant individuals, the researchers were trained in focus group facilitation and used techniques to help ensure that all views were represented.

A semi-structured focus group schedule ${ }^{(24)}$ was designed by the research team, which was based on a literature review and strategies used in previous qualitative studies and informed by the study aims. The schedule explored attitudes to dietary change towards a MD (Supplementary material, Table S2). Discussions began with asking participants if they were aware of the term MD. Participants were then shown an image of a MD food pyramid based on the Oldways MD pyramid $^{(30)}$ and the facilitator gave a short description of the proportions of food groups in this dietary pattern. Following this, attitudes towards adopting a MD were discussed. The schedule was followed as a guide with probes used to stimulate discussion. Where divergence from the schedule occurred due to natural conversation, individuals were encouraged to share their views that were of 
1 other issues that they felt were relevant. Focus groups were held at informal settings including community centres and the research centre and lasted approximately 90 minutes.

4 Subsequent to the first focus group, the transcript was reviewed by the research team to ensure the desired data were being captured. After eight focus groups, progress was again reviewed to assess if any areas required further exploration and if coverage included a sufficiently socio-demographically diverse sample. As a consequence, future participants were asked to comment on their understanding of a 'Mediterranean diet' and to describe the associated dietary pattern. A number of focus groups were also arranged in rural locations at this stage $(n=3)$, to ensure a full range of geographical locations were covered. Data collection continued until no new findings or themes were identified in the data collected ${ }^{(31)}$. Twelve focus groups were conducted with group size ranging from 2-11 participants and an average of 6 participants. Each participant took part in one group.

\section{Data analysis}

Focus group discussions were audio recorded, transcribed verbatim and analysed using an inductive thematic approach as outlined by Braun and Clarke ${ }^{(32)}$. This approach involved two researchers (SM, CME) reading and cross comparing transcripts to enable familiarisation with the data and to generate initial codes (words/ short phrases). Following this, a coding framework was agreed by the research team and applied to transcripts by SM. Related codes were grouped into themes. Themes were then reviewed to ensure they were clear and distinct and were named and defined. Data was analysed at the semantic level to provide a descriptive account of participant views ${ }^{(32,33)}$. An additional member of the research team who was not involved in data collection (MMK) checked and compared the codes to confirm the reliability of the analysis ${ }^{(34)}$ and discrepancies were discussed until full agreement was reached. NVivo software (version 10, QSR International) was used to manage the coded data. Quotations were used to represent views and are presented in italics and referenced as (Participant number, gender, focus group number). Quotations were selected that exemplified views from a range of groups and illustrated the concepts found within the data. Interactions between participants were largely complementary ${ }^{(35)}$ and there were no obvious negative cases among groups ${ }^{(36)}$, therefore views towards a MD are representative of the group as a whole. While a formal comparison of views between individuals of different genders or from different geographical locations was not an aim of this study, data revealed few obvious differences. 


\section{Results}

3 The recruited sample (Table 1), included 67 adults (40 females, 27 males) with mean age 64.0 years. Most participants were overweight or obese, with a mean Body Mass Index (BMI) of 28.8 $\mathrm{kg} / \mathrm{m}^{2}$ and the majority had other CVD risk factors, with $67.2 \%$ reporting high blood pressure and $68.7 \%$ reporting high cholesterol. A minority (40.3\%) stated that they were aware of the MD. Participant MDSs ranged from 0-6 points. The mean MDS was 2.3, indicating that, overall, the sample had low adherence to a MD. Most participants stated that being at increased CVD risk caused them to think about their diet $(83.6 \%)$ and reported that they would consider making dietary changes due to this increased risk $(94.0 \%)$.

Some participants were aware of the term MD and generally it was associated with sunshine and a hot climate and foods including fruit and vegetables, salads, pasta, fish, wine, olive oil and bread. Participants largely associated the MD with healthy eating, consumption of fresh food and preparation of meals. Knowledge of the specific composition of this dietary pattern, however, was limited. Attitudes towards adopting a MD varied, with some individuals feeling that they could make changes towards it and others stating that it was very different to their usual diet and that they would find it challenging. The main themes identified from the analysis were (i) barriers to general dietary change (Table 2) and (ii) barriers specific to MD adoption (Table 3). Barriers are presented alongside recommendations for future interventions to encourage adoption of a MD.

\section{Barriers to general dietary change}

Overall there was a perception of expense towards following a MD, in particular due to the cost of key components such as olive oil, fish and fresh fruit and vegetables. It was felt that it would be particularly difficult for those on lower incomes to adopt this dietary pattern.

"It is more expensive I'd say because you have more fruit and all these things" (050; Female; FG11)

Some participants expressed concern over availability of certain components of the diet, specifically feeling that fresh fish and fruit and vegetables are limited in supermarkets, which would discourage them from purchasing these foods. The wide availability of fast-food restaurants was also frequently mentioned by urban groups. It was felt that being surrounded by an unsupportive eating environment would be a hindrance to following a MD. 
1 “If they're going to improve us all, they're going to have to try and give us fresher food" (043;

2 Female, FG9)

“There's four or five different pizza companies and that many Chinese, they deliver all these leaflets, it's temptation” (064; Male; FG12)

There was a clear expectation of time commitment for following a MD, as participants felt that it would be time consuming and require additional effort to adopt a MD and therefore may not be convenient for individuals with busier lifestyles.

"I suppose depending on your circumstances at home, but preparation of food, the really only chance you get to put a bit of time in in my house is at the weekend" (001; Male; FG1)

Some participants expressed a lack of awareness of the MD and most expressed a limited knowledge of its composition, which they felt would be a significant barrier to following this

"It's just knowing what it is that you really should be eating, and I must admit that's surprised me, the red meat at the very very top, and the poultry and fish” (040; Female; FG8)

Most participants highlighted that a lack of cooking skills would prohibit people from following a MD and felt that many people would not have the skills required to follow a MD or have the ability to translate information provided on the dietary pattern into everyday meals.

Many participants also highlighted that the amount and conflicting nature of media coverage on

diets would discourage them from following this advice and making dietary changes towards a MD.

"That's one of the big problems is that every result you see, within a year or so the whole thing's reversed back over. So people have been demotivated from getting involved in anything to do with diet" (031; Male; FG7) 
1 and that it would be challenging to adopt a diet that is different to what they had been brought up

2 with and become used to.

"You've grown up with one particular type of food and the way things are prepared and then to start introducing... I think it would be very very hard" (005; Male; FG1)

Some participants were resistant to dietary change, with the view of not wanting to be restricted and to be able to enjoy eating the foods they want to eat. Participants mentioned that, being in the later stages of life, often individuals are less willing to make dietary changes.

"If you like the food, enjoy it. My motto is now, I'm coming 70, I'll eat whatever I want and enjoy it” (064; Male; FG12)

\section{Barriers specific to MD adoption}

Consistently among participants there was a perceived difficulty of living in a colder climate for following a MD. Participants' perception of a MD was of a diet pattern predominantly containing salads and fruit and vegetables which they felt would not be satisfying in a colder climate, where the preference would be towards warm meals, which were perceived as providing a higher satisfaction.

“...Come the cold November nights, I don't see that people would be that keen to follow a Mediterranean diet, to be quite honest” (049; Male; FG10)

It was also apparent that there was a perceived impact on body weight. Several participants perceived components of the MD, including olive oil and nuts, to be fattening and associated them with weight gain. These participants held negative attitudes towards increasing their intake of these MD components for this reason.

"I do love nuts but they're quite high in calories" (029; Female; FG6)

Additionally, acceptability of a MD was discussed and some participants mentioned components of a MD that would be difficult to adopt or reduce their intake of to follow a MD. Some participants felt that it would be difficult to incorporate olive oil into their diet due to disliking the taste and as using it as a dressing did not appeal to them. Some participants expressed that they would not 
1 consume nuts, other than salted varieties or that they avoided nuts due to difficulties chewing and

2 digesting them. A number of individuals expressed a dislike for fish and it was perceived by some

3 participants that fish is not frequently consumed in NI, other than battered fish. Most participants

4 felt that it would be difficult in NI for people to reduce their red meat consumption, holding the view that it is consumed in greater amounts and traditionally makes the basis of meals in NI. While these views were held by some participants, others had a higher acceptability towards different MD components, with some individuals stating that they would use olive oil as their main cooking fat, some sharing that they enjoy consuming nuts and/or fish and a few participants expressing that they infrequently consume red meat. It was also felt by a number of participants that it would be difficult for people in NI to reduce their intake of processed foods, due to the perception that many people rely on such foods due to a lack of cooking skills, busy lifestyles or having a low income. Additionally, several participants felt it would be difficult to reduce their intake of sweet foods, with individuals expressing an enjoyment of the taste and getting pleasure out of eating them.

"It's probably the unhealthy nuts we would be inclined to eat here, salted peanuts" (024; Female; FG5)

“A lot of people here don't eat fish...It's mainly fish and chips” (015; Male; FG3)

“You make the dinner and if it's not a big chop or sausages, even mince and onions, it's not a proper dinner" (009; Female; FG4)

Furthermore, Cultural differences in diet were mentioned as a barrier, as participants felt that the MD differs widely from the typical diet in NI. Participants expressed that it would not be natural to people in NI to reduce their intake of red meat and consume more fish, olive oil and fruit and vegetables as it would not be the cultural norm and would be difficult to follow a dietary pattern different to that dictated by cultural influences. It was apparent from discussions that foods eaten as part of a traditional meal in NI, including red meat with potatoes and vegetables, have been engrained as part of the eating culture in NI over time. Individuals stated that they had been surrounded by this way of eating and expressed a strong attachment towards it, which would make dietary change very challenging. 


\section{Discussion}

3 Findings revealed the main challenges associated with following a MD. Knowledge of the specific composition of a MD was limited, therefore there is need for further education on this dietary pattern that offers significant health benefits for this at risk group. Barriers to general dietary change were identified. Most of these barriers are consistent with barriers to general healthy eating that are established in the dietary change literature ${ }^{(15-19)}$ and have been identified as barriers to following a MD in other non-Mediterranean populations ${ }^{(20,21,37)}$. Some previously identified barriers to healthy eating including social activities and family food preferences, however ${ }^{(17,21,37)}$, were not a major concern to participants in this study. These studies were carried out with younger adults who may place greater significance on social barriers. Participants had a mean age of 64 years. Family food preferences may not be a major barrier as, at this age, participants may not have children living with them and influencing food decisions. More important may have been the increased health risks associated with ageing, and therefore both spouses may be willing to make dietary changes. Additionally, these other studies included healthy adults who may have less family support for dietary change than those at high CVD risk. The present research demonstrates further barriers specific to following a MD in a Northern European population that need to be considered.

This data suggests that cultural identity has a significant impact on food choice and that people may distance themselves from a dietary pattern that is not the cultural norm. Literature widely supports that cultural values and beliefs in relation to food greatly influences dietary behaviour ${ }^{(38)}$. This has important implications for how the MD is presented to non-Mediterranean populations. MD advice should be tailored to adapt to different cultural eating patterns and traditional views surrounding food. Participants felt that it would be difficult to follow a MD in a colder climate. As the MD was perceived to be made up of salads and fruit and vegetables, practical information is needed to educate individuals on the specific components of the MD, highlighting that it also includes warm, hearty meals and therefore may be more acceptable in a colder climate. The concern of some participants that consumption of olive oil and nuts would cause weight gain is a common perception that has lead to research being carried out that demonstrated that consumption of these MD components does not promote adiposity ${ }^{(5)}$. Such views could be overcome through education about the health benefits of replacing saturated fat with monounsaturated and polyunsaturated fats ${ }^{(39)}$. Acceptability was an identified barrier to following a MD in this population. It is well established that acceptability of a food, particularly taste is strongly linked to dietary behaviour ${ }^{(40)}$. Research suggests that increased exposure to foods can lead to increased consumption ${ }^{(41)}$. Acceptability of the 
methods of consuming foods or alternative meal ideas. Overall, the barriers identified highlight that education on the specific components and health benefits of the MD and provision of culturally tailored, low cost, quick and easy to prepare recipes and meal ideas are needed to help individuals at high CVD risk from a Northern European population to integrate a MD into their normal eating patterns.

Two small qualitative studies in healthy adults also reported that a colder climate, a perceived impact on body weight, acceptability and cultural differences are important barriers to MD adoption in a Northern European population ${ }^{(20,21)}$. Findings from this study contribute to this limited 0 evidence base of factors effecting MD adoption in non-Mediterranean populations and extend this 1 knowledge to views of individuals at high CVD risk. Interventions to encourage dietary behaviour change towards a MD in non-Mediterranean regions are limited in number ${ }^{(13,14)}$ and are needed to explore the transferability of this dietary pattern. In the development of such interventions, it is important to identify and address any dietary related barriers which could limit the intervention impact, as it has been shown that perceived barriers to following a healthy diet are associated with dietary behaviour ${ }^{(40,42)}$. This formative research is therefore essential to help enhance the

A major strength of this work was the sample size obtained, which was relatively large for qualitative research, and the recruitment across different genders and geographical areas. This helped to gather a broad range of views, as individuals may differ in their receptiveness to dietary change. Factors which may limit the generalisability of findings should be considered. The recruited sample included more females than males, therefore findings may be more representative of female views. This is an important consideration as males are at higher risk of developing CVD than females $^{(43)}$ so it is important to capture their views and as views may differ between genders. Females are generally considered to be more amenable to making dietary changes than males ${ }^{(44)}$. The majority (94\%) of this sample, however, were willing to make dietary changes and data revealed few obvious differences between male and female views. It is therefore unlikely that this bias significantly impacted findings. Some findings may be specific to a Northern Irish population, therefore similar studies in other regions would be beneficial. It must also be considered that individuals who volunteer to participate in diet-focused research may be more motivated to make dietary changes than the general at risk of CVD population. As with most qualitative research, findings are not empirically generalisable ${ }^{(36)}$, however they provide an insight into participant views and can be used to develop concepts, understand phenomena and make theoretical propositions that are relevant to other populations and settings ${ }^{(36)}$ and findings are consistent with previous research. 
1 Focus groups typically consist of 6-12 people $^{(45)}$. The small size of some included focus groups (n

$2 \leq 5)$ could therefore also be a limiting factor. Focus groups were each planned to include approximately eight individuals, but expected numbers were sometimes not met due to the nature of working in the community. It has been suggested, however, that small groups encourage group cohesion, help to maintain focus on the topic and help to ensure participation from all individuals $^{(45)}$. Additionally, a reflexive account of the research process would have increased the reliability of findings ${ }^{(36)}$, however researchers established a sense of commonality with participants to minimise their potential impact on discussions ${ }^{(29)}$ and three researchers were involved in data analysis. Limitations associated with measurement of MD adherence should also be considered. The FFQ and MDS were not previously used or validated, they were however based on a validated measure ${ }^{(26)}$. A specific limitation of shortening the questionnaire includes assessing consumption of legumes in combination with vegetables, which will have limited the scope for considering consumption of this key MD component. Perceptions on consumption of legumes could also have been explored further during focus group discussions.

In conclusion, this research indicates that although there was already some awareness of the term MD in this Northern European sample at high CVD risk, knowledge of the specific composition of a MD may be limited. Barriers associated with healthy eating in general were evident, including perception of expense, concern over availability, expectation of time commitment, limited knowledge, lack of cooking skills, amount and conflicting nature of media coverage on diets, changing established eating habits and resistance to dietary change. Further barriers specific to following a MD, however, were also identified, including perceived difficulty of living in a colder climate, perceived impact on body weight, acceptability of a MD and cultural differences. The knowledge gaps and barriers captured here will be used to inform the development of a MD intervention which will then be piloted in the study population. Key elements of this tailored intervention will include:

- Education on the specific MD components, emphasising that it includes warm meals

- Education on the health benefits of the MD and types of fat

- Provision of low cost, quick and easy to prepare, culturally tailored MD recipes

31 Consideration of these elements may be useful to researchers planning MD interventions in other

32 Northern European populations to enhance the potential impact of the intervention and therefore 33 could inform development of a public health program which successfully facilitates dietary behaviour change towards a MD. Findings also emphasise the importance of tailoring public health 
nutrition education for the target population though addressing knowledge gaps, attitudes and barriers.

\section{Transparency declaration}

The lead author affirms that this manuscript is an honest, accurate, and transparent account of the study being reported.

\section{References}

1. Wang $\mathrm{H}$, Naghavl $\mathrm{M}$, Allen $\mathrm{C}$ et al. Global, regional, and national life expectancy, all-cause mortality, and cause-specific mortality for 249 causes of death, 1980-2015: a systematic analysis for the Global Burden of Disease Study 2015. Lancet. 2016; 388: 1459-1544.

2. Mente A, de Koning L, Shannon HS et al. A systematic review of the evidence supporting a causal link between dietary factors and coronary heart disease. Arch Intern Med. 2009; 169: 659-669.

3. Sofi F, Macchi C, Abbate R et al. Mediterranean diet and health status: an updated meta-analysis and proposal for a literature-based adherence score. Public Health Nutr. 2014; 17: 2769-2782.

4. Estruch R, Ros E, Salas-Salvado J et al. Primary prevention of cardiovascular disease with a Mediterranean diet. N Engl J Med. 2013; 368: 1279-1290.

5. Estruch R, Martínez-Gonzalez MA, Corella D et al. Effect of a high-fat Mediterranean diet on bodyweight and waist circumference: a prespecified secondary outcomes analysis of the PREDIMED randomised controlled trial. Lancet. 2016; 4: 666-676.

6. Martínez-González MA, Salas-Salvadó J, Estruch R et al. Benefits of the Mediterranean Diet: Insights From the PREDIMED Study. Prog Cardiovasc Dis. 2015; 58: 50-60.

7. de Lorgeril M, Salen P, Martin JL et al. Mediterranean diet, traditional risk factors, and the rate of cardiovascular complications after myocardial infarction: final report of the Lyon Diet Heart Study. Circulation. 1999; 99: 779-785.

8. Vincent-Baudry S, Defoort $C$, Gerber $M$ et al. The Medi-RIVAGE study: Reduction of cardiovascular risk factors after 3 month-intervention with a Mediterranean type diet or a low-fat diet. Am J Clin Nutr. 2005; 82: 964-971.

9. Bach-Faig A, Berry EM, Lairon D et al. Mediterranean diet pyramid today. Science and cultural updates. Public Health Nutr. 2011; 14(12A): 2274-2284.

10. Hoffman R \& Gerber M. Evaluating and adapting the Mediterranean diet for non-Mediterranean populations: a critical appraisal. Nut Rev. 2013; 71: 573-584.

11. Bates B, Cox L, Nicholson S et al. (2016) National Diet and Nutrition Survey. Results from Years 5-6 (combined) of the Rolling Programme (2012/13 - 2013/14). https://www.gov.uk/government/uploads/system/uploads/attachment_data/file/551352/NDNS_Y5 6_UK_Main_Text.pdf (accessed 18th May 2017). 
12. Papadaki A \& Scott JA. The impact on eating habits of temporary translocation from a Mediterranean to a Northern European environment. Eur J Clin Nutr. 2002; 56: 455-461.

13. Papadaki A \& Scott JA. Follow-up of a web-based tailored intervention promoting the Mediterranean diet in Scotland. Patient Educ Couns. 2008; 73: 256-263.

14. Logan KJ, Woodside JV, Young IS et al. Adoption and maintenance of a Mediterranean diet in patients with coronary heart disease from a Northern European population : a pilot randomised trial of different methods of delivering Mediterranean diet advice. J Hum Nutr Diet. 2010; 23: 30-37.

15. de Almeida MD, Grace $P$, Afonso $C$ et al. Healthy eating in European elderly: concepts, barriers and benefits. J Nutr Health Aging. 2001; 5: 217-219.

16. Gough B \& Connor MT. Barriers to healthy eating amongst men: A qualitative analysis. Soc Sci Med. 2006; 62: 387-395.

17. Macdiarmid JI, Loe J, Kyle J et al. "It was an education in portion size', Experience of eating a healthy diet and barriers to long term dietary change. Appetite. 2013; 71: 411-419.

18. Pridgeon A \& Whitehead K. A qualitative study to investigate the drivers and barriers to healthy eating in two public sector workplaces. J Hum Nutr Diet. 2013; 26: 85-95.

19. Fitzgerald N \& Spaccarotella K. Barriers to a Healthy Lifestyle: From Individuals to Public Policy_An Ecological Perspective. J Ext. 2011; 47: 1FEA3.

20. Middleton G, Keegan R, Smith MF et al. Implementing a Mediterranean diet intervention into a RCT: Lessons learned from a non-Mediterranean based country. J Nutr Health Aging. 2015; 19 : 1019-1022.

21. Papadaki A, Thanasoulias A, Pound R et al. Employees' Expectations of Internet-Based, Workplace Interventions Promoting the Mediterranean Diet: A Qualitative Study. J Nutr Educ Behav. 2016; 48: 706-715.

22. Bates B, Lennox A, Prentice A et al. (2015) National Diet and Nutrition Survey Rolling Programme (NDNS RP) Results from Years 1-4 (combined) for Northern Ireland (2008/092011/12). https://www.food.gov.uk/sites/default/files/ndns-ni-full-report.pdf (accessed 18th May 2017).

23. Campbell NC, Murray E, Darbyshire J et al. Designing and evaluating complex interventions to improve health care. BMJ. 2007; 334: 455-459.

24. Draper A \& Swift JA. Qualitative research in nutrition and dietetics: data collection issues. J Hum Nutr Diet. 2010; 24: 3-12.

25. Jourard SM. The Transparent Self: Self-disclosure and Well-being. $1^{\text {st }}$ ed. New York: Van Nostrand; 1964.

26. Martínez-González MA, Garcia-Arellano A, Toledo E et al. A 14-item mediterranean diet assessment tool and obesity indexes among high-risk subjects: The PREDIMED trial. PLoS ONE. 2012; 7: e43134. 
27. Orsavova J, Misurcova L, Ambrozova JV et al. Fatty Acids Composition of Vegetable Oils and Its Contribution to Dietary Energy Intake and Dependence of Cardiovascular Mortality on Dietary Intake of Fatty Acids. Int J Mol Sci. 2015; 16: 12871-12890.

28. Delgado-Lista J, Perez-Martinez P, Lopez-Miranda J et al. Long chain omega-3 fatty acids and cardiovascular disease: a systematic review. Br J Nutr. 2012; 107 Suppl 2: S201-13.

29. Manderson L, Bennett E \& Andajani-Sutjahjo S. The social dynamics of the interview: age, class and gender. Qual Health Res. 2006; 16: 1317-1334.

30. Oldways Preservation \& Exchange Trust (2009) Oldways Mediterranean diet pyramid. http://oldwayspt.org/resources/oldways-mediterranean-diet-pyramid (accessed 19 ${ }^{\text {th }}$ May 2017).

31. Morse JM. The significance of saturation. Qual Health Res. 1995; 5: 147-149.

32. Braun V \& Clarke V. Using thematic analysis in psychology. Qual Res Psychol. 2006; 3: Suppl 3-5.

33. Fade SA \& Swift JA. Qualitative research in nutrition and dietetics: data analysis issues. Hum Nutr Diet. 2010; 24: 106-114.

34. Harris JE, Gleason PM, Sheean PM et al. An introduction to qualitative research for food and nutrition professionals. J Am Diet Assoc. 2009; 109: 80-90.

35. Kitzinger, J. The methodology of focus groups: The importance of interaction between research participants. Sociology of Health \& Illness. 1994; 16: 103-121.

36. Pilnick A \& Swift JA. Qualitative research in nutrition and dietetics: assessing quality. J Hum Nutr Diet. 2011; 24: 209-214.

37. Hardin-Fanning F. Adherence to a Mediterranean diet in a rural Appalachian food desert. Rural Remote Health. 2013; 13: 2293.

38. Nestle M, Wing R, Birch L, et al. Behavioural and social influences on food choice. Nutr Rev. 1998; 56: 50-64.

39. Schwab U, Lauritzen L, Tholstrup T et al. Effect of the amount and type of dietary fat on cardiometabolic risk factors and risk of developing type 2 diabetes, cardiovascular diseases, and cancer: a systematic review. Food Nutr Res. 2014; 10: 58.

40. Pinho MGM, Mackenbach JD, Charreire $\mathrm{H}$ et al. Exploring the relationship between perceived barriers to healthy eating and dietary behaviours in European adults. Eur J Nutr. 2017; doi: 10.1007/s00394-017-1458-3.

41. Appleton KM, Gentry RC \& Shepherd R. Evidence of a role for conditioning in the development of liking for flavours in humans in everyday life. Physiol Behav. 2006; 87: 478-486.

42. Lara J, McCrum LA \& Mathers JC. Association of Mediterranean diet and other health behaviours with barriers to healthy eating and perceived health among British adults of retirement age. Maturitas. 2014; 79: 292-298. 
1 43. Lloyd-Jones DM, Larson MG, Beiser A et al. Lifetime risk of developing coronary heart disease. Lancet. 1999; 353: 89-92.

4 44. Wardle J, Haase AM, Steptoe A et al. Gender differences in food choice: the contribution of 5 health beliefs and dieting. Ann Behav Med. 2004; 27: 107-16.

45. Wong LP. Focus group discussion: a tool for health and medical research. Singapore Med J. 8 2008; 49: 256-260. 
Table 1: Focus group participant demographic information ( $\mathrm{n}=67 \mathrm{Max})$

\begin{tabular}{|c|c|}
\hline \multicolumn{2}{|l|}{ Variable } \\
\hline Age in years mean(SD) & $64.0(10.0)$ \\
\hline \multicolumn{2}{|l|}{ Gender n(\%) } \\
\hline Males & $27.0(40.3)$ \\
\hline Females & $40.0(59.7)$ \\
\hline \multicolumn{2}{|l|}{ Geographical location n(\%) } \\
\hline Urban & $49.0(73.1)$ \\
\hline Rural & $18.0(26.9)$ \\
\hline \multicolumn{2}{|l|}{ Relationship status n(\%) } \\
\hline Single & $5.0(7.5)$ \\
\hline Married & $40.0(59.7)$ \\
\hline Divorced & $8.0(11.9)$ \\
\hline Widowed & $11.0(16.4)$ \\
\hline Not reported & $3.0(4.5)$ \\
\hline Current smokers n(\%) & $8.0(11.9)$ \\
\hline Weight (kg) mean (SD) & $80.7(16.4)$ \\
\hline BMI $\left(\mathrm{kg} / \mathrm{m}^{2}\right)$ mean $(\mathrm{SD})$ & $28.8(4.5)$ \\
\hline \multicolumn{2}{|l|}{ BMI classification (WHO) $n(\%)$} \\
\hline Normal weight & $12.0(17.9)$ \\
\hline Overweight & $23.0(34.3)$ \\
\hline Obese & $24.0(35.8)$ \\
\hline Not reported & $8.0(11.9)$ \\
\hline Reported high blood pressure n(\%) & $45.0(67.2)$ \\
\hline Reported high cholesterol n(\%) & $46.0(68.7)$ \\
\hline Taking blood pressure or cholesterol medication n(\%) & $44.0(65.7)$ \\
\hline \multicolumn{2}{|l|}{ Responsible for household shopping $\mathrm{n}(\%)$} \\
\hline Self & $39.0(58.2)$ \\
\hline Partner/ spouse & $12.0(17.9)$ \\
\hline Other & $2.0(3.0)$ \\
\hline Shared & $13.0(19.4)$ \\
\hline Not reported & $1.0(1.5)$ \\
\hline \multicolumn{2}{|l|}{ Responsible for household cooking $n(\%)$} \\
\hline Self & $39.0(58.2)$ \\
\hline Partner/spouse & $9.0(13.4)$ \\
\hline Other & $2.0(3.0)$ \\
\hline Shared & $16.0(23.9)$ \\
\hline Not reported & $1.0(1.5)$ \\
\hline Aware of Mediterranean diet n(\%) & $27.0(40.3)$ \\
\hline High CVD risk evoked thought about diet n(\%) & $56.0(83.6)$ \\
\hline \multicolumn{2}{|l|}{ Extent diet is related to CVD risk $n(\%)$} \\
\hline Not related at all & $0.0(0.0)$ \\
\hline Somewhat related & $10.0(14.9)$ \\
\hline Don’t know & $16.0(23.9)$ \\
\hline Related a little & $16.0(23.9)$ \\
\hline Related a lot & $23.0(34.3)$ \\
\hline Not reported & $2.0(3.0)$ \\
\hline Would consider dietary changes due to high CVD risk $n(\%)$ & $63.0(94.0)$ \\
\hline Mediterranean Diet Score mean (SD) & $2.3(1.6)$ \\
\hline \multicolumn{2}{|l|}{ MDS category $n(\%)$} \\
\hline $0-2$ points & $39(58.2)$ \\
\hline $3-5$ points & $24(35.8)$ \\
\hline $6-8$ points & $2(3.0)$ \\
\hline Not reported & $2(3.0)$ \\
\hline
\end{tabular}


Table 2: Barriers to general dietary change reported by adults at high risk of CVD from a Northern European population and recommendations for future interventions to encourage MD adoption

\begin{tabular}{|c|c|c|}
\hline Barrier & Representative quotes & $\begin{array}{l}\text { Recommendations for future } \\
\text { MD interventions }\end{array}$ \\
\hline $\begin{array}{l}\text { Perception of } \\
\text { expense }\end{array}$ & $\begin{array}{l}\text { - "It is more expensive I'd say because you have more fruit and } \\
\text { all these things" (050; Female; FG11) } \\
\text { "It (Olive oil) is dear and anybody that's on a low income, you } \\
\text { can't use it constantly" (010; Female; FG2) } \\
\text { - "Fish has got very, very expensive, I find" (002; Male; FG1) }\end{array}$ & $\begin{array}{l}\text { Budgeting tips/MD cost } \\
\text { comparison with typical } \\
\text { westernised diet/ Low cost } \\
\text { recipe ideas }\end{array}$ \\
\hline $\begin{array}{l}\text { Concern over } \\
\text { availability } \\
\text { (Low availability } \\
\text { MD foods/ high } \\
\text { availability fast } \\
\text { food) }\end{array}$ & $\begin{array}{l}\text { - "Some supermarkets say they have fresh fish but it doesn't look } \\
\text { - } \quad \text { fresh and when you open it, it stinks" (025; Female; FG5) } \\
\text { we're getting them all far too late...if they're going to improve } \\
\text { us all, they're going to have to try and give us fresher food" } \\
\text { (043; Female, FG9) } \\
\text { "There's four or five different pizza companies and that many } \\
\text { Chinese, they deliver all these leaflets, it's temptation" (064; } \\
\text { Male; FG12) }\end{array}$ & $\begin{array}{l}\text { Discuss local sources of foods/ } \\
\text { Tips for eating out - healthier } \\
\text { restaurants or menu options }\end{array}$ \\
\hline $\begin{array}{l}\text { Expectation of } \\
\text { time } \\
\text { commitment }\end{array}$ & $\begin{array}{l}\text { - "People seem to have less time now" (044; Female; FG9) } \\
\text { "It's all about really convenience" "I suppose depending on } \\
\text { your circumstances at home, but preparation of food, the really } \\
\text { only chance you get to put a bit of time in in my house is at the } \\
\text { weekend" (001; Male; FG1) } \\
\text { "It's not taking time. I see it with my daughter... and her hours } \\
\text { are so long in the day, she comes home at night, the last thing } \\
\text { she wants to do is cook" (024; Female; FG5) }\end{array}$ & $\begin{array}{l}\text { Explanation that components of } \\
\text { the MD can be purchased pre- } \\
\text { prepared/ Provide recipes for } \\
\text { meals that take }<30 \text { mins }\end{array}$ \\
\hline $\begin{array}{l}\text { Limited } \\
\text { knowledge }\end{array}$ & $\begin{array}{l}\text { - "I haven't heard of it but I presume the Mediterranean diet is } \\
\text { simply the diet that people who live around the Mediterranean } \\
\text { eat" (049; Male; FG10) } \\
\text { "It's just knowing what it is that you really should be eating, } \\
\text { and I must admit that's surprised me, the red meat at the very } \\
\text { very top, and the poultry and fish" (040; Female; FG8) } \\
\text { "It looks lovely but what would you do with what? What is a } \\
\text { Mediterranean diet or meal out of that?" (003; Male; FG1) }\end{array}$ & Education \\
\hline $\begin{array}{l}\text { Lack of cooking } \\
\text { skills }\end{array}$ & $\begin{array}{l}\text { - "But that's one of the things that goes against, the pattern of } \\
\text { not cooking" (019; Female; FG4) } \\
\text { "A lot of people today don't really get into the kitchen and get } \\
\text { to know about the basics of cooking" (063; Male; FG12) } \\
\text { "We all need to eat fruit and vegetables but converting it into } \\
\text { something-is the problem and going home and preparing it" } \\
\text { (005; Male; FG1) }\end{array}$ & Cooking demonstrations \\
\hline $\begin{array}{l}\text { Amount and } \\
\text { conflicting } \\
\text { nature of media } \\
\text { coverage on diets }\end{array}$ & $\begin{array}{l}\text { - "That's one of the big problems is that every result you see, } \\
\text { within a year or so the whole thing's reversed back over. So } \\
\text { people have been demotivated from getting involved in } \\
\text { anything to do with diet" (031; Male; FG7) } \\
\text { "Don't you think that every magazine you lift, every paper, } \\
\text { there's diets in it, there's eat this and do you know, it all } \\
\text { becomes too much, I think" (041; Female; FG8) } \\
\text { "Nearly everything you touch, one day it's okay and the next } \\
\text { it's not, and I just decided 'right, I'm just not going to worry } \\
\text { too much"' (019; Female; FG4) }\end{array}$ & $\begin{array}{l}\text { Provide evidence based } \\
\text { information }\end{array}$ \\
\hline $\begin{array}{l}\text { Changing } \\
\text { established } \\
\text { eating habits }\end{array}$ & $\begin{array}{l}\text { - "But habit is so powerful" (036; Male; FG7) } \\
\text { - "You've grown up with one particular type of food and the way } \\
\text { things are prepared and then to start introducing... I think it } \\
\text { would be very very hard" (005; Male; FG1) } \\
\text { "And it's what you're brought up to have, if you know what I } \\
\text { mean"(030; Female; FG6) }\end{array}$ & $\begin{array}{l}\text { Advice on adapting meals to be } \\
\text { more Mediterranean }\end{array}$ \\
\hline $\begin{array}{l}\text { Resistant to } \\
\text { dietary change }\end{array}$ & $\begin{array}{l}\text { - "If you like the food, enjoy it. My motto is now, I'm coming 70, } \\
\text { I'll eat whatever I want and enjoy it" (064; Male; FG12) } \\
\text { "I don't think that a lot of people would want to change their } \\
\text { ways" (040; Female; FG8) } \\
\text { "I think we're just too late in life now to change" (016; Male; } \\
\text { FG3) }\end{array}$ & $\begin{array}{l}\text { Suggest small dietary changes } \\
\text { to make }\end{array}$ \\
\hline
\end{tabular}


Table 3: Barriers specific to MD adoption reported by adults at high risk of CVD from a Northern European population and recommendations for future interventions to encourage MD adoption

\begin{tabular}{|c|c|c|}
\hline Barrier & Representative quotes & $\begin{array}{l}\text { Recommendations for } \\
\text { future MD interventions }\end{array}$ \\
\hline $\begin{array}{l}\text { Perceived difficulty of } \\
\text { living in a colder } \\
\text { climate }\end{array}$ & $\begin{array}{l}\text { - } \quad \text { "A lot of this food is good in a nice warm environment } \\
\text { where you're sitting and the sun's beaming in" }(005 ; \\
\text { Male; FG1) } \\
\text { "Our food is potatoes, hot meals, warm meals, meat, } \\
\text { potatoes, things that keep you warm, stews that warm you } \\
\text { up inside, whereas the Mediterranean consciousness is } \\
\text { different. They're eating things like vegetables, salads, } \\
\text { tomatoes, all of those things, which are okay in the } \\
\text { summer, but come the cold November nights, I don't see } \\
\text { that people would be that keen to follow a Mediterranean } \\
\text { diet, to be quite honest" (049; Male; FG10) } \\
\text { "I think because we're such a cold country too you want } \\
\text { warmer foods" (030; Female, FG6) }\end{array}$ & $\begin{array}{l}\text { Education about components } \\
\text { of MD/ Provide MD recipe } \\
\text { ideas adapted for a colder } \\
\text { climate }\end{array}$ \\
\hline $\begin{array}{l}\text { Perceived impact on } \\
\text { body weight }\end{array}$ & $\begin{array}{l}\text { - "They put this olive oil all over their pasta, and they said } \\
\text { that that was why they had a lot of weight on, because } \\
\text { obviously it's that has the calories in it" (021; Female; } \\
\text { FG4) } \\
\text { "I stay away from them (nuts) because I'm calorie } \\
\text { counting" (036; Male; FG7) } \\
\text { "I do love nuts but they're quite high in calories" (029; } \\
\text { Female; FG6) }\end{array}$ & $\begin{array}{l}\text { Education about the benefits } \\
\text { of monounsaturated and } \\
\text { polyunsaturated fats }\end{array}$ \\
\hline $\begin{array}{l}\text { Acceptability of a } \\
\text { Mediterranean diet }\end{array}$ & $\begin{array}{l}\text { - "That particular type of fat, oil drizzled. It doesn't do it } \\
\text { - } \quad \text { "It's probably the unhealthy nuts we would be inclined to } \\
\text { eat here, salted peanuts" (024; Female; FG5) } \\
\text { "A lot of people here don't eat fish...It's mainly fish and } \\
\text { chips" (015; Male; FG3) } \\
\text { "You make the dinner and if it's not a big chop or } \\
\text { sausages, even mince and onions, it's not a proper } \\
\text { dinner" (009; Female; FG4) } \\
\text { "One of the other things that would work against this is } \\
\text { the sort of thing of not cooking, people buying ready- } \\
\text { made” (019; Female; FG4) } \\
\text { "I think we all have a sweet tooth, don't we? At some part } \\
\text { of the day you're going to eat maybe something, a biscuit } \\
\text { or something like that" (032; Male; FG7) }\end{array}$ & $\begin{array}{l}\text { Tasting sessions/ Demonstrate } \\
\text { methods of consuming food } \\
\text { in different ways/ Alternative } \\
\text { meal and snack ideas }\end{array}$ \\
\hline Cultural differences & $\begin{array}{l}\text { - } \quad \text { "It's not a normal diet for us in this country at all" (002; } \\
\text { - } \quad \text { "Bute; FG1) } \\
\text { lot of red meat" (023; Female; FG4) } \\
\text { "Historically, the Irish have never been particularly good } \\
\text { at getting much beyond potatoes and cabbage. It's } \\
\text { fascinating that. One of the really interesting things to me } \\
\text { is that if you go to parts of Ireland where fishing is a } \\
\text { significant activity, you will not find that the local people } \\
\text { eat fish" (035; Male, FG7) }\end{array}$ & $\begin{array}{l}\text { Provision of culturally } \\
\text { tailored MD meal ideas and } \\
\text { recipes/ Different labelling of } \\
\text { the dietary pattern }\end{array}$ \\
\hline
\end{tabular}




\section{Supplementary material}

\section{Demographic Questionnaire}

Focus group number:

Date:

Many thanks for agreeing to participate in this research study. Before we begin the focus group discussion, please take a few minutes to complete the following questions about you and your diet. All information you provide is anonymous and strictly confidential.

What is your date of birth?

Age (yrs):

Gender:

Male

Female

What is your postcode?

Relationship status: Single $\square \quad$ Co-habiting $\square \quad$ Married $\square \quad$ Divorced

What is your occupation?

What is your current weight?

What is your height?

Do you smoke? $\quad$ Yes $\square \quad$ No $\square$

If yes, how many do you smoke each day?

If no, did you ever smoke? $\quad$ Yes $\square \quad$ No $\square$

Has your doctor/nurse ever told you that you have high blood pressure?

Yes $\square \quad$ No $\square$

Has your doctor/nurse ever told you that your blood cholesterol was high?

Yes $\square \quad$ No $\square$

Do you take any medications to reduce your cholesterol level or blood pressure?

Yes $\square \quad$ No $\square$

If yes, can you remember the names of the medications? (Please list below) 
The next few questions ask about your diet.

Who does most of the shopping in your household?

You $\square$

Spouse/partner

Other person

Shared

If other person, please specify their relationship to you

Who does most of the cooking in your household?

You $\square \quad$ Spouse/partner $\square \quad$ Other person $\square \quad$ Shared $\square$

If other person, please specify their relationship to you

Have you heard of the Mediterranean diet before today?

Yes $\square \quad$ No $\square$

Has realising you are at an increased risk of heart disease made you think about your diet? Yes No $\square$

To what extent do you think your diet is related to your risk of heart disease? Please circle your response.

$\begin{array}{lllll}1 & 2 & 3 & 4 & 5\end{array}$

Not related at all Somewhat related Don't know Related a little Related a lot

Would you consider making dietary changes because you are at increased risk of heart disease?

Yes $\square \quad$ No $\square$ 
Please put a tick $(\checkmark)$ in the box to indicate how often, on average, you have eaten the specified amount of each food during the past year.

\begin{tabular}{|c|c|c|c|c|c|c|c|c|c|}
\hline \multirow[t]{2}{*}{ FOODS AND AMOUNTS } & \multicolumn{9}{|c|}{ AVERAGE USE LAST YEAR } \\
\hline & $\begin{array}{l}\text { Never or } \\
\text { less than } \\
\text { once/month }\end{array}$ & $\begin{array}{l}1-3 \\
\text { per } \\
\text { month }\end{array}$ & $\begin{array}{l}\text { Once } \\
\text { a } \\
\text { week }\end{array}$ & $\begin{array}{l}2-4 \\
\text { per } \\
\text { week }\end{array}$ & $\begin{array}{l}5-6 \\
\text { per } \\
\text { week }\end{array}$ & $\begin{array}{l}\text { Once } \\
\text { a day }\end{array}$ & $\begin{array}{l}2-3 \\
\text { per } \\
\text { day }\end{array}$ & $\begin{array}{l}4-5 \\
\text { per } \\
\text { day }\end{array}$ & $\begin{array}{l}6+ \\
\text { per } \\
\text { day }\end{array}$ \\
\hline $\begin{array}{l}\text { Olive oil/Rapeseed oil } \\
\text { (1 tablespoon) }\end{array}$ & & & & & & & & & \\
\hline $\begin{array}{l}\text { Fruit and natural fruit juice } \\
\text { (1 portion }=1 \text { apple/banana } \\
\text { (80g), small glass juice }(150 \mathrm{ml})\end{array}$ & & & & & & & & & \\
\hline $\begin{array}{l}\text { Vegetables not including } \\
\text { potatoes but including } \\
\text { raw/cooked vegetable, salad, } \\
\text { peas, beans or lentils } \\
\text { ( } 3 \text { tablespoons } / 80 \mathrm{~g})\end{array}$ & & & & & & & & & \\
\hline $\begin{array}{l}\text { Oily fish such as mackerel, } \\
\text { salmon, trout, herring, } \\
\text { kippers or sardines } \\
\text { (1 fillet/small fish or } 140 \mathrm{~g})\end{array}$ & & & & & & & & & \\
\hline $\begin{array}{l}\text { Wine } \\
\text { (1 small glass } / 125 \mathrm{ml})\end{array}$ & & & & & & & & & \\
\hline $\begin{array}{l}\text { Red meat including beef, } \\
\text { pork, lamb, sausages, ham, } \\
\text { bacon, meat pies and other } \\
\text { meat products } \\
\text { ( } 1 \text { medium serving) }\end{array}$ & & & & & & & & & \\
\hline $\begin{array}{l}\text { Wholegrain bread, rice or } \\
\text { cereals including brown rice, } \\
\text { porridge, weetabix, } \\
\text { shreddies, bran flakes, fruit } \\
\text { n' fibre } \\
\text { (1 medium serving) }\end{array}$ & & & & & & & & & \\
\hline $\begin{array}{l}\text { Nuts } \\
\text { (1 small handful) }\end{array}$ & & & & & & & & & \\
\hline
\end{tabular}


Table S1: 8-point Mediterranean diet score used to determine participant adherence to a Mediterranean diet

\begin{tabular}{ll}
\hline FFQ items & Criteria for 1 point
\end{tabular}

1. Olive oil/ Rapeseed oil (1 tbsp.)

$\geq 4-5 /$ day

2. Fruit and natural fruit juice $(1$ portion $=1$ $\geq 2-3 /$ day apple/banana $(80 \mathrm{~g})$, small glass juice $(150 \mathrm{ml})$

3. Vegetables not including potatoes but including $\geq 2-3 /$ day raw/cooked vegetable, salad, peas, beans or lentils (3 tablespoons/80g)

4. Oily fish such as mackerel, salmon, trout, $\geq 2-4 /$ week herring, kippers or sardines (1 fillet/small fish or 140g)

5. Wine (1 small glass $/ 125 \mathrm{ml})$ $\geq 2-4 /$ week $\leq 2-3 /$ day

6. Red meat including beef, pork, lamb, sausages, $\leq 2-4 /$ week ham, bacon, meat pies and other meat products (1 medium serving)

7. Wholegrain bread, rice or cereals including $\geq 2-3 /$ day brown rice, porridge, weetabix, shreddies, bran flakes, fruit $n$ ' fibre (1 medium serving)

8. Nuts (1 small handful) $\geq 2-4 /$ week

Table S2: Sample of questions from semi-structured focus group schedule exploring attitudes to dietary change towards a Mediterranean diet

Semi-structured focus group schedule

- How is this type of diet different to the way you currently eat? (Probe: What are the main differences?)

- Do you think people in Northern Ireland could adopt a diet such as this?

- What components of a Mediterranean diet would people from Northern Ireland find easier/more difficult to adopt in their everyday lives? (Probe: What other components do you think would be easier or more difficult/ Ask about specific components that haven't been discussed e.g. What about Olive oil?)

- What do you feel are the main things that would prevent people from making this type of dietary change? (Probe: Is there anything else that might prevent people from adopting a Mediterranean diet?) 